\title{
On How to Enhance the Integration of the Innovative Spirit in Science and Technology Museum
}

\author{
Yu-chen XI ${ }^{1, a}$, Xin-xiong LIU 2, b and Jie-qiong HANG ${ }^{3, c}$ \\ Department of Mechanical Science and Engineering \\ Huazhong university of science and technology \\ Wuhan,China \\ a 2655518427@qq.com, ${ }^{b}$ xxliu@mail.hust.edu.cn, c 15927180633@163.com
}

\begin{abstract}
Keywords: Innovative spirit, Exhibits planning.
Abstract. The science and technology museum should give full play to its own advantages and strengthen the cultivation of the innovative spirit of the audience while popularizing scientific knowledge. The paper discusses on how the science and technology museum can enhance the integration of the innovative spirit and achieve the aim of cultivating the innovative spirit of the audience. The paper divides the innovative spirit into five aspects: curiosity, practical spirit, passion, inquiry spirit and fearless of failure and proposes that the design of science and technology museum exhibits should correspond to these aspects one by one, and classifies and analyzes typical science and technology exhibits at home and abroad. The science and technology museum should make the innovative spirit better integrate into its construction and achieve the goal of cultivating the innovative spirit of the audience from three aspects including exhibition hall planning, exhibits planning and exhibition education activities.
\end{abstract}

\section{Introduction}

Innovation, as one of the most frequently used terms in the media and even the academia at present, has almost become the synonym for reform, innovation and creation, and been used in all related fields [1]. Meanwhile innovation has become one of the topics that the world pays close attention to and makes a country full of vitality. China has always attached great importance to innovation innovation is the first driving force for development and the strategic support for the construction of a modern economic system. We should aim at the forefront of world science and technology, strengthen basic research, and realize major breakthroughs in prospective basic research and leading original achievements [2]. The lack of strong innovation capability is the difficulty and also the challenge our country is facing in its current development. To rejuvenate our country through science and education, innovation is fundamental.

Innovation literally means setting up or creating new things which consists of innovative spirit, innovation Thinking and knowledge base. Scientific innovation is not only determined by intelligence and knowledge factors, but also non-intelligence factors - innovative spirit which is the internal driving force that runs through people's innovative activities and the core of innovation.

The science and technology museum, as an important infrastructure for the implementation of the strategy of "rejuvenating China through science and education", is an important base for cultivating people's innovative spirit. Therefore, we attach great importance to the function display and the educational significance of science and technology museums in their construction.

It can be clearly seen from the latest tenders for science and technology museums that the construction of exhibits currently has turned from collection of objects and the display of physical carriers to cultivation of the scientific innovative spirit of the audience through science and technology exhibits. However, most domestic science and technology museums guide the audience through a single form-displaying the deeds of celebrities to cultivate the innovative spirit, thus they don't appeal to the audience. 
The education of science and technology museum in our country has done a good job in science popularization, but there are shortcomings in scientific innovation. If scientific innovation is missing, then the strategy of rejuvenating the country through science and education is incomplete. Therefore, how to integrate the spirit of scientific innovation into the design of exhibits and allow the exhibits to achieve the goal of cultivating innovative spirit of the audience under the premise of correctly imparting knowledge is a great challenge for the planning of exhibits at this stage.

\section{The definition of the spirit of innovation}

Kang Youwei once said, "There is no other respect in the peace world except innovators." Innovation is the foundation of a country's development. The innovative spirit is the driving force of people's innovation activities, and it is also the core of innovation. In a word, innovative spirit refers to a comprehensive embodiment of personal quality that on the basis of valuable content which have been learned to take the excellent self quality, such as courage and wisdom, as the catalyst. These qualities include following aspects:

\section{Curiosity}

Curiosity is the beginning of all the innovations. People always first produce curiosity and interest in a thing, and then create a sense of innovation. This is the beginning of cultivating the innovative spirit and the prerequisite of the creation of innovative spirit. Edison once said, "Anything new and unusual can cause a pleasure in imagination. Because this kind of thing makes the mind feel a pleasant surprise and satisfy its curiosity, that is a concept which it has never experiences" [3]. Curiosity is the foundation of the innovators' deep exploration. When the curiosity is the most intense, it is the most active time for innovation and the best time to inspire the innovative spirit.

\section{Practical spirit}

There is no limit to practice and there is no limit to theoretical innovation either [4]. The cultivation of innovative spirit is often an imperceptible process - arousing people's interest in learning and enriching the knowledge reserve of people in the process of learning knowledge and practice to achieve the transformation of qualitative change in knowledge accumulation, naturally form the collision of knowledge sparks, and stimulate the innovative spirit.

Of course, in addition to the objective practice, the innovative spirit is also generated in "accidents" - through the experience of personal practice, the "unintentional" discovery in the process of practice, or the behavior memory which is given by life, is often the source of innovation. Common sense and practical experience are the best catalysts for cultivating innovative spirit. The cultivation of the innovative spirit is also influenced by people or things around it.

\section{Passion}

Jin Ma once said, "Passion can inspire youth's innovative function and inspire everyone's unique innovative spirit." Edison experimented one hundred times with his passion, and finally invented the electric light. Darwin revealed the life rule of the insect world with his passion. The passion of persist in exploring is the necessary catalyst for innovation activities, and is also a kind of emotion that every innovator has.

\section{Inquiry spirit}

"In science, every road should take a step. Finding a path that does not work is a great contribution to science." The road of innovation is not always smooth. It needs continuous research and failure. The process of research and failure is the process of inquiry, and is also the process of deepening the innovative spirit and an important link to embody the innovative spirit. The process of inquiry is one of the most important parts of innovation activities, and inquiry spirit is a necessary quality in scientific innovation activities. 


\section{Being fearless of failure}

It is said that, "Failure is the mother of success." The road of innovation is stumbling and requires constant attempts and failures. We must do not be afraid of failure and find the crux of the problem in failure, then optimize the result of innovation and get the final innovation results. Failure is a compulsory course for every innovator and not be afraid of failure is a spirit of every innovator.

Science and Technology Museum is an important base for cultivating innovative spirit. The basic goal of science and technology exhibits not only is to convey the correct scientific knowledge, but also is an important form of cultivating the audience's curiosity. Compared with the hard education system which refers to impart knowledge at school, learning basic knowledge in the Science and Technology Museum is much easier and more fun, so children are more willing to learn. The Science and Technology Museum teaches audience more knowledge through the display of exhibits. This kind of knowledge is "live". Through this form, the audience could be interest in learning, and their learning enthusiasm and curiosity could be inspired.

The aim of the exhibition in the Science and Technology Museum is to let the audience appreciate the existing science and technology and learn scientific knowledge. At the same time of learning knowledge, we can cultivate the scientific passion of the audience by displaying the scientific thinking way and thinking process to achieve the purpose of encouraging the audience to keep thinking. In addition, we can improve the scientific interest of the audience and to enlighten their scientific innovation spirit through interaction, communication, the guidance of audience's thinking and the cultivating of audience's practical spirit.

Besides showing the principles and achievements of technology, exhibits also need to expound the scientific methods of scientific and technological exploration as well as the scientific exploration process. This is the embodiment of the inquiry spirit, and the embodiment of scientist' $\mathrm{s}$ spirit that is not afraid of failure. The process of exploring a scientific research product is often not smooth but precious. For example, why did Shen Nong taste all kinds of herbs and how to taste all kinds of herbs to write the "Bai Cao Jing"? Why did Li Shizhen go all over the mountains to find a hundred herbs and how to go all over the mountains to find a hundred herbs to write down the Compendium of Materia Medica? These exploration processes are often the core of the innovative spirit of an innovation result. They are also truly needed to be known and learned by the audience when the audience come to the Science and Technology Museum. For audience, it is important to know "Why do we want this result" and "How to achieve the results"? instead of "The final result".

The innovative spirit is a chain which is full of links. After proposing the idea innovation plan, the designer can arouse audience's interest and guide the audience to think through the interest, attraction and interaction of the exhibits. In the design of exhibits, we can achieve the purpose of enlightening and cultivating the innovative spirit of the audience through the aspects of curiosity, practical spirit, passion, inquiry spirit and the spirit that not afraid of failure.

\section{The first exploration of the integration degree of promoting innovation spirit in science and technology museum}

There is a behavioral process when people visit a science and technology museum, which can be divided into three parts comprehensively: before the exhibition, in the exhibition and after the exhibition. We can design one by one according to these three general orientations.

\section{The planning of the science museum}

Compared with studying at school, studying in science and technology museum is more relax and non-oppressive. Audiences can learn selectively according to their own interest. After entering the science and technology museum, the audience will first visit the exhibition area they are interested in so that the exhibition idea, partition concept and the name of the pavilion area all play decisive roles in the construction of science and technology museum.

Concept innovation is the orientation of the construction of science and technology museum, the spiritual orientation of the whole science and technology museum and the key link of the science and 
technology exhibits design. The birth of science and technology museum is a great innovation in the history of museum and the innovation of education concept and exhibition idea, thus bringing great vitality to the museum industry [5]. The aim of the science and technology museum is to promote the scientific spirit and popularize scientific knowledge [6]. Therefore, letting the audience experience the brisk development of national science and technology, injecting new life and new subject to science and technology museum exhibits and cultivating scientific innovation spirit of audience have become the mission and goal of every science and technology museum.

The innovation of the exhibition concept itself is an innovation that endows the science and technology museum with new life and is a soul foundation of a science and technology museum. The process from putting forward idea to the final exhibition in the display area is like writing an article. The exhibition concept of each part is similar to the introduction part of an article, which can point out the ideas and views of the entire article so that the partition exhibition concepts should point out what each sub exhibition area displays and illuminate the highlights of the exhibits in the display area. The name of each exhibition area is also an indispensable part which is similar to the directory or outline of an article with the effect of "finishing touch", just like a good name for a book will leaves a good impression at the first glance. The name of science and technology museum exhibition not only needs to point out the theme, but also adds some mystery or culture color on the frank theme. For example, "the light of Jing Chu" and "Hubei culture" have close meaning and similar theme, but the feeling these two name gives to people are very different. From the overall putting forward of concept to the branch of philosophy, the name of the exhibition, and finally to the design of the exhibits, the entire process is just similar to the structure of an article or a book, each link is indispensable, and need to be finely carved.

\section{The planning of exhibits}

\section{(a) Cultivating curiosity}

Visual attraction. First of all, the existence of visual attraction can't be rejected. We can even say that the visual attraction is the first feeling attraction. When come to the display area, if exhibits have a powerful visual attraction, the audience can see it at the first glance with a good first image, which will arouse audience interest in watching the operation to a certain extent. Therefore, the appearance, color, material and the light around the exhibits are indispensable, which play roles in foiling the exhibits.

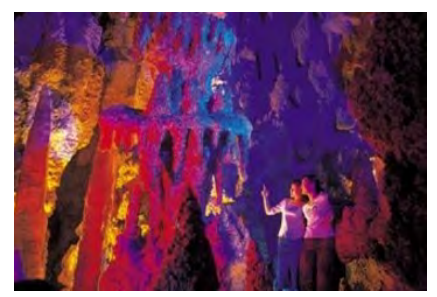

Figure 1. The exhibition item of Karst cave in Shanghai science and technology museum

The exhibition item of Karst cave in Shanghai science and technology museum creates uncanny workmanship geomorphic features in natural world with manual work. The exhibition item is very attractive in visual aspect through realistic construction of light, color, material, which gives the audience visual appeal and shock.

\section{(b) Developing practical spirit}

As the saying goes, "Interest is the best teacher for human beings." A good exhibit must have interest and participation, which let the audience feel "fun" and can participate in the experience at the same time and learn scientific knowledge and enlighten the scientific innovation spirit in the process of participating in the interaction. 


\section{(c) Participating in the interaction and hands-on operation}

The old saying "Getting from the paper is quite shallow, if you want know deep, you should participate in it." emphasizes the importance of practice, which let the audience know the meaning of practice.

Emphasizing the importance of practice. The optical illusion is a classic exhibit in the science and technology museum. It is said that "Observing is better than hearing, participating is better than observing, and recognizing hands-on is better than participating." Eyes can deceive oneself sometimes so that people can only get the correct answer through practicing and verifying personally. Optical illusion is a typical case as shown in the picture below.

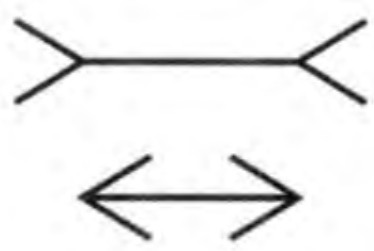

Figure 2. Optical illusion

Observing the picture, we can obviously see that the first line is longer than the second one visually, but the actual measurement comparison shows that the two lines actually have the same length. This is a typical case which shows that what you see is not the real truth and must be proved by practice. This kind of classic case will be exhibited in various science and technology museums, but the museums always put the classic picture of this exhibition on the wall or on the table for the audience to watch basically. In the process of watching, there are few interactive operations between the audience and the exhibits thus not achieving the target expectations of the exhibits. In fact, as long as putting a set of measurement tool beside the picture exhibits and letting the audience use measuring tool to compare the differences between pictures via character or video, the audience can clearly realize the truth "Observing is better than hearing, participating is better than observing, and recognizing hands-on is better than participating." and the importance of practice.

Finding problems in practice. To find the innovation point, we need to find the problem through practice just like the process of finding graphene. Scientists was unable to reach the expected goal after repeated experiments. When thinking the adhesive tape used in modifying the text when we wrote homework in childhood, a simple tape can remove ink from paper, the practice of the tearing behavior formed in people's mind. Associating with the scientific experiments, the audience can connect these two aspects together, which is a method to find problem in the process of practice and the innovation point found in the practice.

Role play. The Seven News Studios is an innovative exhibition item in children's museum at the northern Greenville, USA. The operations are as follows. First of all, children can choose one room among these seven studios including weather forecasts, local news, drama shot, singing, and programming. Step 2: children can accomplish the work tasks such as reporting the news or the weather, singing karaoke, dancing with popular music, and creating original programs according to a work or activity process. At last, the entire process is recorded by a video camera so that the audience can see his own video and buy the video selectively.

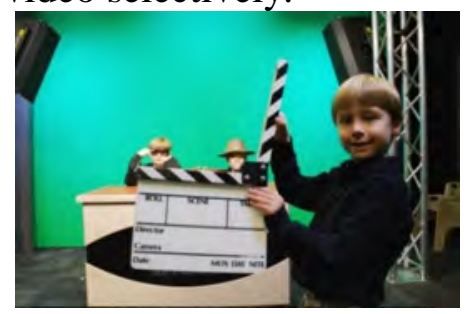

Figure 3. The Seven News Studios

This exhibition item transmits knowledge through practical interactive mode of role play and let audience operate by themselves and be personally on the scene for the whole process through the 
vivid scene and process design. Through the hands-on education concept, let the audience practice personally and obtain pleasure in practice. What's more, through practice, the audience's manipulative ability is improved and guide the interest orientation of the audience at the same time, which let the audience find what they are interested in among different kinds of industries and find their own goals and can find innovative point beyond the goal, thus cultivating the creative spirit of the audience.

The exhibition item "The world in animals' eyes" in Shanghai science and technology museum is composed of different animal head models. The audience can get into different animal head models and experience different worlds seen from different animals' eyes. This exhibition improves audience participation through role play. Although many people know that the world is different from different animals' eyes, less of them know how the world is different from their eyes. Through the form of role play, the audience can see the world through animals' eyes by hands-on practice. What's more, it lets the audience feel and summarize what they see, which will make the audience understand and remember more easily than conveying in written form.

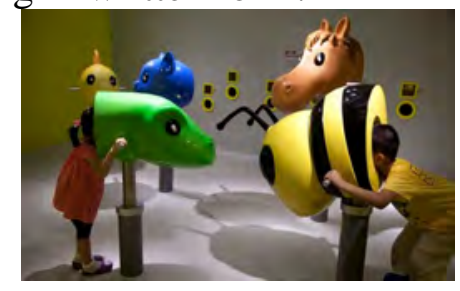

Figure 4. The world in animals' eyes

The display form of role play lets the audience practice personally on the scene through the creation of scene and role. This exhibition item can better motivate the audience to think and let the audience understand, learn and remember scientific knowledge in the practice of interaction, experience the charm of science, cultivate the practical spirit, arouse the interest of the audience, and plant the seed of innovation spirit.

\section{(d) Cultivating passion and stimulating audiences}

Characteristic science and technology achievements in regional innovation. Regional science and technology museum can appropriately increase the technological innovation achievements of the region and launch attractive exhibits with local characteristics integrating the local cultural background. Regional innovation achievements can give local audiences a sense of affinity, which can shorten the sense of distance between the audience and the scientific achievements. At the same time, visitors can feel the sense of pride of the region when they visit the science and technology museum, which will ignite their passion for scientific innovation to some extent.

Celebrity deeds. Celebrity deed is a way to ignite the audience's enthusiasm. Celebrity deed can not only heighten the audience's admiration for celebrities, but also plant the kindling of innovation spirit in the audience heart. However, although many science and technology museums have exhibits about celebrity deeds, most of them just places related exhibition board of celebrities in the exhibition hall, and illustrates the related stories of celebrities with a single form, which is lack of interest and enlarges the sense of distance with the audience.

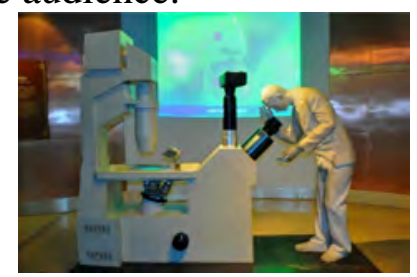

Figure 5. Celebrity laboratory

Celebrity laboratory in Shanghai science and technology museum actualizes the life scenes and experimental scenes of celebrities, which makes the celebrity story no longer exist only in the paper so that the audience can see the exploration process before celebrities putting forward an innovation 
achievement in their lab, thus greatly shortening the sense of distance between the audience and celebrities and enhancing the cognition degree and admiration of the audience. However, the exhibits only make the celebrity experiment model, but the content and achievement are presented with the form of video playing, which lacks the interaction with the audience and the interest of exhibits.

Showing celebrity deeds can actualize the celebrities' laboratory, let celebrity stories come out from book and shorten the distance between the audience and celebrities. First of all, this can show the exploring experiment of celebrities and focus on celebrities' exploring process, which let the audience feel the exploring spirit and innovative spirit of celebrities. Secondly, let celebrities "come to life". Some of the classic experiments done by celebrities can be hands-on operated by the audience in practice. Celebrities no longer appear in the forms of pictures, video and model, but can "come to life" through interactive method. In the experimental process of the audience, celebrities can guide them, which makes celebrity's personality and behavior more remarkable and gives kindness to the audience, thus shortening the distance with the audience and arousing the audience's enthusiasm and germinating of innovation spirit at the same time.

Physical display. Physical display can also bring attraction and shock power to the audience visually.

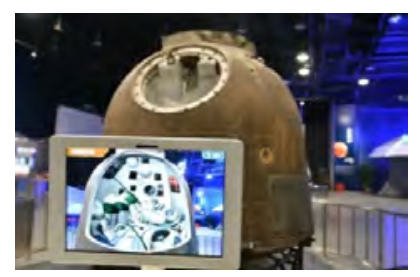

Figure 6. The re-entry capsule of Shenzhou I Spaceship

This exhibition is made up of the actual objects, operation platform and fence of the re-entry capsule of Shenzhou I Spaceship. This exhibition shows the re-entry capsule of Shenzhou I Spaceship to the audience through physical display to show the advanced space technology of China. Physical display is often more attractive and powerful than model display. What it shows is the innovation results of China's technological innovation. This kind of physical exhibition will give the audience an emotional and visual impact, thus arousing their interest and passion for science and germinating their innovative spirit.

Science and technology museum exhibits can show the existing technical achievement through physical display, which can bring the audience new and most advanced science and technology in modern times and new technology brings the extraordinary achievement. At the same time, it can break the original knowledge reserve and cognition degree of the audience and let the audience learn science and technology and knowledge and abound with the longing for future and the sense of national pride at the same time, which is a way to ignite passion audience and cultivate audience's passion, thus achieving the goal of igniting the audience and cultivating the creativity of the audience.

\section{(e) Cultivating a spirit of exploration}

Series design. Serializing exhibits from scientific principles to science and technology to technology applications, which guides audience to think step by step and make a complete and systematic series design, thus being more conducive to audience watching and associating. The single principle model will make the audience feel boring while scientific terminology will also let the audience feel difficult to understand, like learning mathematics, an answer of a simple example doesn't represent students can master all knowledge and be invincible when answering questions. Quite on the contrary, by summarizing various types of questions and forming a series of question types and answering thinking, students can answer the questions with high proficiency. 


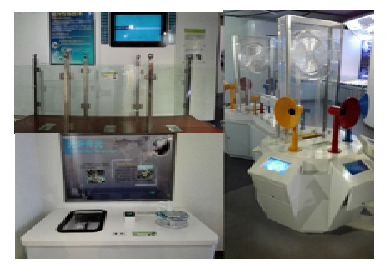

Figure 7.Optical fiber

Taking optical fiber as an example, this innovation achievement with principles, science and technology and modern technology application can be made as serialized design - the transmission principle of light, the invention of optical fiber, the modern applications of optical fiber. Through such serialized exhibits design, let the audience understand and absorb step by step, give full play to the influence brought by technology innovation achievements, which can let the audience germinate more ideas, stimulate their desire to continue innovation, which is real things that science and technology museum have to do-- to be a guider of cultivating science ideology. The optical fiber serialized exhibits in Wuhan science and technology museum are divided into three parts: fiber optic light, optical fiber communications and optical fiber sensing technology ranging from basic application of the optical fiber to the development of optical fiber technology application, serialized exhibits can let the audience generate association more easily and be easy to think.

Classic Case. Traditional classic technology exhibits are too numerous to mention one by one, and are displayed in science and technology museums in different regions. However, because the exhibition methods are generally more popular and are pretty much the same as a whole, it not only affects the liking degree of the audience, but also reduces the benefit of science and technology museum and weaken the purposiveness. For example, the Three Gorges Dam and the model cars displayed in the showcase in Wuhan science and technology museum only show the model in a single way, which are so boring. Therefore, it is imperative to innovate the museum's traditional exhibits.

The scientific and technological achievement of classic exhibits is very typical. However, a lot of science and technology museums only show their scientific and technological achievement when showing classic exhibits while ignoring the exploring process behind the technological achievement. Behind every scientific and technological innovation achievement, there is a long exploring process, which can not be ignored in the technological achievement. It is the embodiment of the innovative spirit and the concrete exploration of scientific method. For example, for the extinction of dinosaurs, although so far do not have a definite conclusion, each theory is not imagined but has exploring experience and the scientific method. It is also a highlight part in display design- the exploring spirit and exploring method behind a theory.

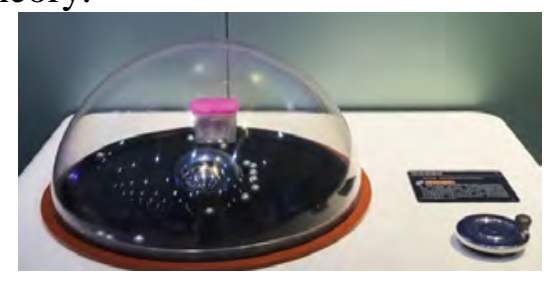

Figure 8. Electrostatic Touch Ball

Electrostatic Touch Ball is a classic exhibit of static electricity that many science and technology museums will display. This exhibit demonstrates the principle of electrostatic induction, the operation is as follows. The first step, the audience turn the handwheel and make the metallic ball with high voltage in the center of the spherical electrode move towards high pressure under the effect of top terminal electrostatic induction. After contacting, it obtains positive electricity and then bounces off the top terminal under the repulsion effect between the same electric charge. In the second step, when the ball moves to the edge of the disk and comes into contact with the earth electrode on the edge, the positive charge will be neutralized. After that, it will obtain negative electricity under the effect of top terminal electrostatic induction. And the little ball will roll back and forth moving in circles. 
Audience can see the ball rolling back and forth when operating this exhibit, but they can only learn related principles through literal statement. For the audience, their cognition of static exists only in this exhibit, but they are confused in the source, principle and exploring process of static because they ignore the exploring process of static. In the exhibit design, the exploring process of a technology can be realized through practice. Starting from the discovery of a problem by a famous scientist, relevant small scientific experiments are set up to allow the audience to conduct multiple experiments on their own to obtain experimental data and experimental results. In order to ensure the accuracy of the audience's experiment results, the science and technology museum can control the experimental data in a certain range through technical means. Through practice, it can guide the audience to go through the process of scientific and technological exploration again and understand the stories behind the technological achievements to cultivating the audience's spirit of exploration. Guiding the operation of the audience through interactive means can emphasize the process of inquiry, which is conducive to focusing on the cultivation of the spirit of inquiry, and is one of the ways to promote the spirit of innovation.

\section{(f) Cultivating a spirit of not fearing failure}

Zhengzhou science and technology museum has exhibit of Luban lock. Luban lock is a kind of educational toys, which is easy to disassemble but difficult to install. It is difficult for people to install Luban lock quickly if they are not familiar with the dismounting principle of Luban lock so that people need unceasingly try and explore. Besides training people's intelligence, Luban lock can also train and cultivate people's spirit of not fearing failure. When designing such exhibits, the science and technology museum can give the audience some hints to let the audience operate under the hints. Secondly, simple assembly of Luban lock lacks interactive feedback which can conduct interaction with the audience in practice and encourage the audience when they fail and praise them when they succeed. Through this interactive mode, the audience is encouraged to continue to practice, and cultivate the audience of not fearing failure.

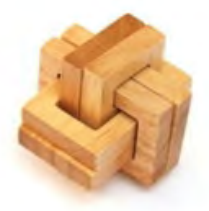

Figure 9. Luban lock

\section{The exhibit and education activity of Science and Technology Museum}

The exhibit and education activity of Science and Technology Museum is often neglected in the design of the museum. But from the original building intention of the museum, exhibition and education activities precisely is a bottleneck to improve the audience's spirit of innovation. After watching the exhibits that they are interested in, the memory curve is decreasing as the time goes on, and the impression of the exhibits will become more and more blurred. Therefore, if we want to further cultivate the audience's innovative spirit, we should pay more attention to the exhibition and education activities of Science and Technology Museum.

(a) laboratory

In fact, when searching for the official website of the Science and Technology Museum, we can find that almost every official website has the words "Science and Technology Museum Laboratory". The Science and Technology Museum always has a "science lab" where audiences can do some scientific experiments at the Science and Technology Museum on weekends or holidays. However, because of the lack of propagation, only a few of people know about this.

The Science and Technology Museum is an ideal place for informal learning, and it is also a powerful complement to the formal education in schools. Therefore, the Science and Technology Museum can cooperate with schools to develop students' knowledge and expand the education contents of school. Schools can encourage and organize students to participate in these laboratory 
activities at weekends to expand students' knowledge and improve their practical ability. This kind of activities can let students get out of textbooks and receive new science and technology more quickly to understand the new scientific and technological situation. In addition, it is conducive to cultivate students' curiosity, practice spirit, inquiry spirit, passion for scientific innovation and the desire for knowledge from all aspects. Through the training of these aspects, we can achieve the purpose of cultivating the audience's innovative spirit.

\section{(b) Seminar}

The Science and Technology Museum is an important base for the cultivation of the spirit of innovation. So the Science and Technology Museum can hold some seminars and set up maker space to let the audience practice the scientific content that they are interested in. Audience can discuss and brainstorm with people with the same interest, and they can work together in a short time to make some preliminary design of the model to carry out the autonomous inquiry. In the process of making these models, participants can cultivate their practical ability and enhance their spirit of innovation.

Secondly, because of the attention of our country to the technological innovation, a series of innovative competitions, such as Maker Space, are held vigorously. As an important base for cultivating innovative spirit, the Science and Technology Museum can also encourage and organize a series of innovative competitions. It can also hold thematic competitions in the seminar or maker space to encourage healthy competition among participants and give certain rewards. Through these competitions, participants can spark new ideas and stimulate their innovative spirit.

\section{(c) Souvenir}

The scientific knowledge of the scientific and technological exhibitions in the Science and Technology Museum is relatively simple and can also produce simple physical models. As a result, when designing the exhibits, you can set up a notice, which lists the required materials of making a physical model, next to the science and technology exhibits to encourage the audience to prepare the materials by themselves and go home and continue the experiment. Or we can Pack the prepared experimental materials and instructions and put them in the souvenir shop to let the audience purchase them. Through these ways, we can carry out exhibition and education activities. In addition, and the audience's innovative spirit can be cultivated through the way of experimentation by hands.

\section{Summary}

Developing the country through science and education includes not only knowledge popularization, but also scientific innovation. The innovative spirit is the core of scientific innovation and is also the fundamental condition of developing the country through science and education. Therefore, as an important infrastructure for implementing the strategy of developing the country by science and education, the Science and Technology Museum needs to improve the innovative spirit through scientific and technological exhibits on the basis of correct popularization of scientific knowledge for the public.

This paper analyzes how the Science and Technology Museum develop the innovative spirit of the audience and discusses several ways to realize it. Then summarize the whole article, the innovation is showed in the following aspects:

- The spirit of innovation is divided into five aspects: curiosity, practice spirit, passion, inquiry spirit and fear of failure. This paper suggests that In the exhibition design of Science and Technology Museum, it is necessary to design in these aspects, and classifies and analyzes typical scientific and technological exhibits at home and abroad.

- The Science and Technology Museum should consider three aspects, the planning of the exhibition hall, the planning of the exhibits and the activities of the exhibition and education, to integrate innovative spirit into the construction of the museum, so as to achieve the purpose of cultivating the innovative spirit of audience. 
At present, this set of design methods has been applied in the planning of a provincial Science and Technology Museum. However, because the building has not been built yet, there is no physical picture and feedback from the public to verify it.

The innovative spirit is a large category, and it requires a long-term process to be cultivated. How to integrate the innovative spirit into scientific and technological exhibits is a question which deserves deep study and needs continuous research, supplement and perfection.

\section{References}

[1] Yuan Wangdong: Science and Technology Innovation and Social Development (Hunan University Press, Changsha 2007).

[2] Xi Jinping: report to the General Assembly at the 19th National Congress of the Communist Party of China (2017)

[3] Edison: The definition of Rock's ingenious wisdom. (Commercial Press, 1980).

[4] Xi Jinping: report to the General Assembly at the 19th National Congress of the Communist Party of China (2017)

[5] Li Chunfu and Li Danyi: The Research of Science and Technology Museum Exhibits and the Design of Display Form. Packaging engineering. 16 (2010), p 62-65.

[6] Xi Jinping: report to the General Assembly at the 19th National Congress of the Communist Party of China ( 2017) 